\title{
Charity Self-Regulation: A Commentary on NCVO Code of Ethics 2018
}

\begin{abstract}
In July 2018, the National Council for Voluntary Organisations ('NCVO') released a draft version of the Code of Ethics for the Charity Sector ('CoE'). This proposed code is currently under revision. The purpose of this policy-paper is to provide a brief commentary on the CoE highlighting its normative strengths and weaknesses, proposing on each of the latter suggestions for improvement.
\end{abstract}

Keywords: Charity Self-Regulation, NCVO, Code of Conduct, Accountability. Author: Domenico Carolei

Affiliation/Contact Details: PhD Candidate/Teaching Assistant, School of Law - Centre for Citizenship, Civil Society and Rule of Law (CISRUL), University of Aberdeen, UK (domenico.carolei@abdn.ac.uk) 


\section{Introduction}

In July 2018, the National Council for Voluntary Organisations ('NCVO') released a draft version of the Code of Ethics ('CoE') for the charity sector (NCVO, 2018a). The latter is a brand new selfregulatory instrument defined by charities for charities at sectoral level. The CoE represents the output of a review panel that was set up as part of a programme of work agreed by charities in the aftermath of safeguarding failures that took place in the first half of 2018 (Weakley, 2018). In January 2018, the Financial Times revealed that hostesses were groped and sexually harassed during a men-only fundraising dinner organised by the London-based charity the Presidents Club (Marriage, 2018). Only one month after, The Times revealed that senior Oxfam staff in Haiti had paid earthquake survivors for sex in 2011 and that Oxfam subsequently failed to report the abuse to other aid agencies and to relevant judicial authorities ( $\mathrm{O}^{\prime}$ Neill, 2018). In the aftermath of the Oxfam scandal, the chair of NCVO declared that "more can and must be done" to protect both charity beneficiaries and public trust in the sector (Cooney, 2018). Indeed, according to some measures public trust in British charities has declined since the scandals broke out (Thomson Reuters Foundation, 2018). In March 2018, the Charity Commission held a summit with charities, umbrella bodies (including NCVO) and the Office for Civil Society where everyone committed to work together to achieve the highest standards of safeguarding. The themes agreed for priority action were: a) leadership, culture and values; b) law, regulation and the statutory framework; c) capacity and capability in charities around safeguarding; d) reporting, accountability and transparency (Charity Commission, 2018a). Within this process NCVO gave birth to the CoE. The first draft of the $\mathrm{CoE}$ has been discussed during a roundtable at which many and different charities (in terms of size, type and area of activity) took part (NVCO, 2018b). The CoE has been drafted using as a general point of guidance existing self-regulatory instruments including the Nolan Principles of Public Life, the Code of Ethics for Museums, the Charity Governance Code and the NHS Constitution for England (NVCO, 2018b). In July 2018, NCVO launched a public consultation on the first draft of the $\mathrm{CoE}$. This public consultation was aimed at ensuring that the final version of the code is based on feedback from the widest possible range of charities and stakeholders, and formally closed in September 2018 (NVCO, 2018b). The Charity Commission has submitted its opinion on the CoE in October 2018 (Charity Commission, 2018b). 
The purpose of this policy-paper is to provide a commentary on the CoE, evaluating the extent to which it addresses regulatory concerns and institutional dysfunctions that traditionally affect selfregulation in promoting charity accountability. Over the past decades, there has been a proliferation of self-regulatory initiatives worldwide (Warren \& Lloyd, 2009). Despite the increasing popularity, charity self-regulation has been criticised due to difficulties in codifying beneficiary accountability (Lloyd, 2005), design flaws in terms of institutional architecture (Hammad \& Morton, 2011) and because of low level of norm-compliance (Traxle, Greiling \& Hebesberger, 2018). These criticisms cast doubts on the effectiveness of self-regulation in promoting charity accountability. It is, therefore, important to evaluate whether the proposed version of the $\mathrm{CoE}$ addresses adequately longstanding problems that affect self-regulation in enacting charity accountability. To do so, this policy-paper is structured as follows. First, it provides a definition of charity self-regulation. Subsequently, it offers a detailed taxonomy of common regulatory concerns and institutional dysfunctions that affect self-regulation in enacting charity accountability. While doing so, this policy-paper lays down a series of normative expectations against which the regulatory content of the $\mathrm{CoE}$ will be assessed. Finally, focus will be brought to the regulatory content of the $\mathrm{CoE}$ in order to highlight its normative strengths and weaknesses. A series of proposals to increase the normative quality of the CoE will be outlined within the conclusive section.

\section{Charity self-regulation}

As opposed to government-driven legislation, that applies equally to all charities in a given jurisdiction (Breen, Dunn \& Sidel, 2016), charity self-regulation can be appropriately defined as

“(...) a collective action by a significant number of non-state actors to shape their own behavior and that of others in a (sub)sector through the establishment of norms, standards, and credible commitments, supported by mechanisms that induce adherence, which has substantial legitimacy across the sector and with governments, stakeholders, and citizens. The goals of self-regulation may vary from avoiding state regulation to producing fundamental behavioral change in a sector, and the mechanisms can range from relatively non-prescriptive voluntary codes to mandatory accreditation which may, in effect, serve as a license to operate"(Phillips, 2013).

Firstly, self-regulation can have the advantages of representing a low-cost and relatively rapid way to motivate sector change without needing statutory intervention or regulatory instruments to come into effect. It is a "collective action" made by a "significant number of non-state actors". The 
definition of voluntary standards is the result of a joint effort made at industry-level, rather than at firm-level (Gunningham \& Rees, 1997). In other words, self-regulation can have dual-nature: it exists at intra-organisational level (known also as "individual-self-regulation") where a charity defines on its own internal policies to regulate staff behavior, and it also exists at interorganisational level (known also as "collective self-regulation") in which a group of peers define norms for the sector as a whole.

Collective self-regulation is a process undertaken $b y$ a conspicuous number of charities to set normative standards for charities without any formal State intervention in the regulatory process. On a practical level, self-regulatory initiatives exist in a variety of forms: codes of conduct, certification/accreditation schemes, information schemes, working groups and awards (Warren \& Lloyd, 2009). The common thread among all self-regulatory initiatives is that they rely on the voluntary participation of charities (Warren \& Lloyd, 2009). As to self-regulation's goals, the above definition makes explicit reference "to producing fundamental behavioral change in a sector." Obviously, the main goal that self-regulation can serve is a normative one, that is: promoting the best accountability practices rendering them more systematic among charities. In that respect, self-regulation is more than a simple tool of accountability as it is a process linked to sectoral identity and normative views on organisational behavior (Ebrahim, 2003). In addition, the goals towards which self-regulation is directed are based on what motivates charities to adopt a brand new self-regulatory instrument (Obrecht, 2012). There are typically three drivers behind the adoption of self-regulation: low stakeholder trust, the threat of restrictive state regulation and the need for capacity building and learning (Obrecht, 2012). In the specific instance of the CoE, the charity scandals that took place in the first half of 2018 triggered widespread scepticism in the British third-sector and the need for capacity-building and learning among charities. As documented in the introduction of this policy-paper, the CoE's goal is to achieve the highest standards of safeguarding and to restore public trust in the charity sector.

At the international level, there have been more than 300 initiatives developed by charities, suggesting that self-regulation is a rapidly evolving trend (Warren \& Lloyd, 2009). In United Kingdom, charity self-regulation is a well-established regulatory trend (Dunn, 2016). It has been estimated that there are over 130 self-regulatory initiatives developed at sectoral level, the most well-known is the Charity Governance Code (Dunn, 2016). Diverse self-regulatory initiatives 
exist, from quality standards programs to third-party accreditation schemes, and they encompass many aspects of organisational life ranging from fundraising (Fundraising Regulator) to digital engagement (Charity Digital Code). Contemporary co-regulation ${ }^{1}$ effort between the Charity Commission and umbrella bodies like NCVO proposes that this approach is used as a regulatory infrastructure to fill normative gaps in standards and governance (Dunn, 2016).

\section{Charity self-regulation: regulatory concerns and institutional dysfunctions}

Despite the increasing popularity, self-regulation has been criticised both by scholars and practitioners.

A common concern about charity self-regulation is that voluntary norms are often vague and lack definition, especially in relation to the issue of beneficiary accountability: a charity's accountability towards those people that charities provide services to or speak on behalf of in policy forums (Lloyd, 2005). In particular, it was noted that the vast majority of self-regulatory initiatives do not even mention the word "beneficiary" and, in those where they do, voluntary norms do not provide a detailed description of how charities fulfil their responsibilities towards their beneficiaries (Lloyd \& Las Casas, 2005). Essentially, beneficiary accountability is rarely supported by self-regulation implementation guidelines, in contrast to detailed guidelines concerning financial reporting and donor accountability (Lloyd \& Las Casas, 2005). On that account, CIVICUS recommends charities to include accountability to beneficiaries in voluntary standards, pointing out that "accountability to beneficiaries is a growing area of concern for civil society organisations" (Guénéheux \& Bottomley, 2014).

In terms of institutional architecture, self-regulatory instruments have been criticised as they often do not offer any compliance and enforcement mechanisms, leading to inconsistent implementation (Hammad \& Morton, 2011). Even when self-regulatory instruments are equipped with adequate enforcement mechanisms, it is not always clear how effectively these actually operate (Hammad \& Morton, 2011). In that respect, it was submitted that two conditions are required to prove the

\footnotetext{
${ }^{1}$ Breen, Dunn \& Sidel (2016) on pp. 2-3 identify a third, emerging and hybrid type of regulation: "co-regulation". The latter is defined as follows: "(...) between the polar ideals of pure statutory and non-statutory regulatory regimes lies the emerging sphere of co-regulation or hybrid regulation. This regulatory form tends to be developed by or on behalf of the sector (like self-regulation) but with the active funding or participation of the state (like statutory regulation)"
} 
strength of self-regulation: clear standards for behaviour and credible enforcement mechanisms (Prakash \& Gugerty, 2010). On the one hand, clear and stringent behavioural standards enhance the credibility of self-regulation by facilitating norm-compliance among charities (Prakash \& Gugerty, 2010). On the other hand, the presence of an explicit monitoring/enforcement system is meant to further enhance the credibility of compliance and to provide information about adherence to standards to external stakeholders (Prakash \& Gugerty, 2010).

As to the reasons and obstacles behind non-compliance, empirical evidence suggests that the proliferation of self-regulation is substantially increasing the workload for charities and that verification and compliance criteria are too rigid to accommodate organisational diversity (Crack, 2016). To elaborate, there has been an overwhelming proliferation of self-regulatory initiatives and existing instruments were often developed in isolation from one another: the result is that their normative content tends to overlap (Crack, 2016). In this context, small charities have requested the establishment of specific voluntary norms that would suit their structures as self-regulation norms seem to be designed following a one-size-fits-all approach, neglecting sectoral diversity (Crack, 2016).

\section{A commentary on NCVO Code of Ethics}

The CoE provides a voluntary framework for charities, their governing bodies, staff members and volunteers. This voluntary framework is built upon four key ethical principles: beneficiary first, integrity, openness and right to be safe. Each of these principles is accompanied by a set of practical actions that charities should undertake in their day-to-day work beyond existing legal requirements. According to the drafters, the CoE summarises "what many charities already do and what all charities aspire to do" (NCVO, 2018a). As to its scope, the CoE targets all charities regardless of their type, size and area of activity (NCVO, 2018a). With regard to implementation and monitoring, the $\mathrm{CoE}$ gives charities a wide margin of discretion because it does not set up a monitoring body empowered to oversee norm-compliance at sectoral level. Essentially, it is up to individual charities to decide how to implement the $\mathrm{CoE}$ and how monitoring can be best carried out at organisational level (NCVO, 2018a). 


\subsection{CoE normative strengths: beneficiaries first, complementary and normative diversification}

The CoE presents many positive aspects within its regulatory content.

First, it puts charity beneficiaries at the core of its framework. By doing so, the CoE addresses the regulatory imbalance that has been detected in many existing self-regulatory instruments. More specifically, it emphasises that charities should constantly commit to practice beneficiary accountability even when this might have an initial negative impact on charity reputation and/or leadership (NCVO, 2018a). In order to operationalise this principle, charities are required to undertake the following practical actions: 1) identify clearly who the charity beneficiaries are; 2) ensure that the view of beneficiaries is listened to and taken into account through participatory approaches (engagement and communication); 3) ensure that all policies at organisational level are drawn up keeping in mind the best interests of beneficiaries (NCVO, 2018a).

Secondly, the CoE deals with the uncontrolled proliferation of self-regulatory instruments at sectoral level through affirming the principle of complementarity. As documented previously, selfregulatory instruments often duplicate their normative content requiring charities to fulfill and report twice the same voluntary standard to different bodies. Because of this duplication, charities need to make substantial efforts, in terms of human and financial resources, to comply with voluntary standards. In fact, some commentators have argued that the proposed $\mathrm{CoE}$ should be merged into the Charity Governance Code because having two sets of standards could be confusing for charities (Chapman, 2018; Purkis, 2018). In that respect, the drafters made clear that "the code is complementary to existing sector codes such as the Charity Governance Code, as well as individual charities' codes or policies. It is not intended to replace their own definitions of values and codes of conduct" (NCVO, 2018a). Therefore, the CoE supplements existing self-regulatory instruments rather than duplicating or replacing them. In other words, it is only when existing codes are insufficient or inadequate in addressing accountability aspects that the CoE should be used as a point of reference to fill self-regulatory lacunas.

Thirdly, the CoE accommodates sectoral diversity by defining different standards of behaviour, depending on charity's size. As noted above, one of the key criticisms made against voluntary instruments is that they are often drafted following a one-size-fits-all approach. The result is that voluntary standards are applicable exclusively to some types of charity, failing to accommodate 
organisational diversity. The $\mathrm{CoE}$ rejects a one-size-fits-all approach to regulation. Indeed, it lays down different behavioral requirements through normative diversification for big and small charities when it comes to openness. In particular, the code asks charities "to be willing to share information about their work, ensuring it is accessible to all, and publish, or, for the very small charities, at least make available on request: a) annual reports; b) their approach to safe-guarding, bullying and harassment; c) their complaint procedure" (NCVO, 2018a). To elaborate, larger charities are asked to publish this information openly, whereas, small charities have a minimal duty to provide the same information on request.

Lastly, the CoE deals strongly with issues of safeguarding as a response to charity scandals that took place at beginning of 2018. On the one hand, the principle of integrity asks charities to treat everyone who comes in touch with the charity (including through society media) with honesty and respect (NCVO, 2018a). On the other hand, charities are asked, as a matter of safeguarding (right to be safe), to stand against and prevent abuse of power, bullying, intimidation and harassment in all their activities (NCVO, 2018a). To operationalise this principle, it is suggested that charities should undertake continual training courses for staff members and should have an organisational procedure in place to report and handle allegations of misconducts (NCVO, 2018a).

\subsection{CoE normative weaknesses: normative ambiguity and lack of adequate implementation/monitoring system}

One of the most common weaknesses of self-regulation is that voluntary norms can be vague and generic. This vagueness brings about the risk of normative ambiguity that, in turns, creates implications on how voluntary norms should be operationalised in practice. This normative ambiguity has been detected by the Charity Commission, through its opinion on the CoE, in relation to the principle of integrity. According to the charity regulator, this principle has a broad application because it covers many different organisational activities and themes (Charity Commission, 2018b). It is for this reason that NVCO is encouraged to draw out these themes more explicitly: "for example, where the section on integrity touches on resources, if it is intended to encompass social and ethical investment, it would benefit from clearer statements to that effect" (Charity Commission, 2018b). 
The major weakness of the $\mathrm{CoE}$, in the opinion of the author, is the lack of a clear implementation and monitoring system. In terms of institutional architecture, a self-regulatory instrument must be equipped with a credible enforcement mechanism to maximise norm-compliance among charities. However, the $\mathrm{CoE}$ gives charities a wide margin of discretion when it comes to implementing its core principles. In practice, it is up to individual charities to decide how to implement the $\mathrm{CoE}$ and how monitoring can be best carried out at organisational level. The CoE simply states that charities are encouraged to meet its principles or, in case of non-compliance, to "explain why they have not done so" (NCVO, 2018a). However, there is no indication of how charities should justify noncompliance and it is equally unclear to whom charities have to report norm-compliance. The Charity Commission has, in fact, asked to NVCO: "how will this code be promoted, implemented and its adoption monitored? Is NCVO satisfied that it has been sufficiently tested in terms of ease of practical application by this broad range of charities?" (Charity Commission, 2018b).

\subsection{CoE weaknesses of the drawing up process}

A further weakness, in the opinion of the author, lies in the process of drawing up the CoE. While drafting the provisional version of the $\mathrm{CoE}, \mathrm{NCVO}$ could have strengthened its own process for developing this new code, and thus avoided the above mentioned normative weaknesses, by appointing a panel of experts composed by lawyers, charity practitioners and researchers working on self-regulation and by ensuring close involvement of other sector infrastructure bodies. Similarly, it could have been helpful to take into account data (if any were available) on impact and effectiveness of those existing self-regulatory instruments that were used as a general point of guidance to draft the $\mathrm{CoE}$.

\section{Conclusion}

The CoE deals successfully with some longstanding regulatory concerns that affect self-regulation: a) it puts beneficiary accountability at the core of its regulatory content; b) it states clearly its complementary nature to existing sector codes and c) it does diversify voluntary norms depending on charity size. Besides these normative strengths there are, however, two major regulatory weaknesses. First, some voluntary standards are excessively generic and characterised by profound normative ambiguity. Secondly, the lack of a clear monitoring system that oversees compliance at sectoral level could potentially lead to inconsistency in the implementation of the code among 
charities, thus distorting norm-compliance. In order to attenuate these weaknesses, NCVO could take into account the following proposals:

1) Re-defining in clear, explicit and succinct terms those practical actions related to the principle of integrity as recommended by the Charity Commission.

2) Establishing a clear and simplified reporting/disclosure procedure to verify normcompliance together with the creation of an ad hoc monitoring body at sectoral level, ideally composed of charity practitioners themselves, empowered to promote and oversee norm-compliance of the CoE.

3) Launching a pilot case-study with a few purposefully selected heterogenic charities to test whether this provisional version of the CoE could be easily implemented at organisational level prior to formally adopting it.

In the author's opinion, these proposals could certainly contribute to increasing the normative quality of the $\mathrm{CoE}$ and promoting accountability among charities. However, the extent to which these proposals would be used as a point of reference to amend the CoE depends, ultimately, on the will of charities and on the outcome/feedback received from NCVO during the consultation process. It would also be helpful, in my opinion, to constitute a panel of experts as outlined above. It is hoped that the debate towards the adoption of the $\mathrm{CoE}$ will be rapid and that feedback provided by policy-makers, charities and researchers will be adequately taken into account, and lead to normative improvements.

Conflict of interest statement: the author declares that there is no conflict of interest.

Acknowledgements: I am immensely grateful to the policy review editor, Professor Cathy Pharoah and to the anonymous reviewers for their invaluable comments. 


\section{Reference}

Breen, O. B., Dunn, A., \& Sidel, M. (2016) Regulatory Waves: Comparative Perspectives on State Regulation and Self-Regulation Policies in the Nonprofit Sector, Cambridge University

Press.

Chapman, R., (2018) Response to NCVO consultation on a proposed Code of Ethics, https://www.civilsociety.co.uk/people.rosie-chapman.html

Charity Commission (2018a) UK charities commit to strengthening safeguarding culture and capability, https://www.gov.uk/government/news/uk-charities-commit-to-strengtheningsafeguarding-culture-and-capability

Charity Commission (2018b) Government Response: Charity Commission responds to draft Charity Code of Ethics Regulator publishes submission to NCVO consultation on code of ethics, https://www.gov.uk/government/news/charity-commission-responds-to-draft-charity-code-ofethics

Cooney, R. (2018) We must ensure sexual exploitation is not tolerated, says NCVO chair, Third-

Sector, https://www.thirdsector.co.uk/ensure-sexual-exploitation-not-tolerated-says-ncvochair/management/article/1456913

Crack, A. M. (2016) 'Reversing the telescope: Evaluating NGO peer regulation initiatives' Journal of International Development, 28(1): pp. 40-56.

Dunn, R. (2016) 'Eddies and Ties: Statutory Regulation, Co-Regulation and Self-Regulation in Britain' in in Breen, O. B., Dunn, A., \& Sidel, M. (eds) Regulatory Waves: Comparative Perspectives on State Regulation and Self-Regulation Policies in the Nonprofit Sector, Cambridge University Press. pp. 21-44.

Ebrahim, A. (2003) 'Accountability in Practice: Mechanisms for NGOs', World Development, 31(5): pp. 813-829.

Guénéheux, D., \& Bottomley, A. (2014) Accountability for Civil Society by Civil Society: A Guide to Self-Regulation Initiatives. CIVICUS.

Gunningham, N., \& Rees J., (1997) 'Industry Self-Regulation', Law \& Policy (19) 4: pp. 363414.

Hammad, L., \& Morton, B. (2011) Greater Influence, Greater Responsibility: are INGOs' SelfRegulatory Accountability Standards Effective? The North-South Institute.

Lloyd, R. (2005) The Role of NGO Self-Regulation in Increasing Stakeholder Accountability. London. One World Trust. 
Lloyd, R., \& de Las Casas, L. (2005) NGO Self-regulation: Enforcing and Balancing Accountability. London. One World Trust.

Marriage, R. (2018) Men Only: Inside the charity fundraiser where hostesses are put on show, https://www.ft.com/content/075d679e-0033-11e8-9650-9c0ad2d7c5b5

National Council for Voluntary Organisations (2018a) Charity Code of Ethics, https://www.ncvo.org.uk/code-of-ethics-draft

National Council of Voluntary Organisations (2018b) Code of Ethics - How we developed the draft code, https://www.ncvo.org.uk/policy-and-research/ethics

Obrecht, A. (2012) Effective accountability? The drivers, benefits and mechanisms of CSO selfregulation. London: One World Trust.

O' Neill, S. (2018) Minister orders Oxfam to hand over files on Haiti prostitute scandal, https://www.thetimes.co.uk/article/top-oxfam-staff-paid-haiti-quake-survivors-for-sexmhm6mpmgw

Phillips, S. D. (2012) 'Canadian Leapfrog: From Regulating Charitable Fundraising to CoRegulating Good Governance', Voluntas: International Journal of Voluntary and Nonprofit Organizations 23 (3): pp. 808-829

Prakash, A., \& Gugerty, M. K. (2010) 'Trust but verify? Voluntary regulation programs in the nonprofit sector', Regulation \& Governance, 4 (1): pp. 22-47.

Purkis, A., (2018) Does the charity sector need a separate code of ethics? , https://www.civilsociety.co.uk/voices/andrew-purkis-does-the-charity-sector-need-a-separatecode-of-ethics.html\#sthash.tL7SaSrk.dpuf

Traxler, A. A., Greiling, D., \& Hebesberger A. (2018) GRI Sustainability Reporting by INGOs: A Way Forward for Improving Accountability? Voluntas. doi: https://doi.org/10.1007/s11266018-9976-Z

Thomson Reuters Foundation (2018), Britain's trust in charities drops after Oxfam scandal, https://www.reuters.com/article/us-britain-charities-trust/britains-trust-in-charities-drops-afteroxfam-scandal-idUSKBN1GZ2E4

Warren, S., \& Lloyd, R. (2009) Civil Society Self-Regulation: The Global Picture - Briefing paper n. 119. London. One World Trust.

Weakley, K. (2018) 'NCVO publishes draft code of ethics for charities', Civil Society, https://www.civilsociety.co.uk/news/ncvo-publishes-draft-code-of-ethics-for-charities.html 